\title{
Primary and secondary $H / D$ isotope effects in the addition of triazolinedione to 2,5-dimethyl-2,4-hexadiene. Mechanistic insights into the reaction pathways
}

\author{
Georgios Vassilikogiannakis, Manolis Stratakis, and Michael Orfanopoulos \\ Department of Chemistry, University of Crete, Iraklion 71409, Greece \\ E-mail: orfanop@chemistry.uoc.gr
}
Dedicated with appreciation to Professor Gerasimos J. Karabatsos on the occasion of his $70^{\text {th }}$ birthdate

(received 12 Dec 02; accepted 26 May 03; published on the web 26 May 03)

\begin{abstract}
Primary and secondary isotope effects were determined for the reaction of 4-methyl[1,2,4]triazoline-3,5-dione with 2,5-dimethyl-2,4-hexadiene-1,1,1,2',2',2'- $d_{6}$. The results are consistent with the formation of an aziridinium imide intermediate in equilibrium with an open zwitterion. At higher temperatures, the aziridinium imide prevails and can be either transformed to the ene adduct in a slow step, or trapped by the solvent if the reaction is carried out in methanol. At lower temperatures, the entropically favored open zwitterion is formed preferentially, that either polymerizes in chloroform or can be trapped by methanol.
\end{abstract}

Keywords: Ttriazolinedione, ene reaction, isotope effects, reaction mechanism

\section{Introduction}

4-Methyl- and 4-phenyl[1,2,4]triazoline-3,5-dione (MTAD and PTAD, respectively) readily react with conjugated dienes to form [4+2] adducts. ${ }^{1}$ The stereochemistry of the Diels-Alder adducts from the reaction of PTAD with 2,4-hexadienes ${ }^{2}$ and alkoxy-substituted 1,3-butadienes ${ }^{3}$ is consistent with both concerted and stepwise mechanisms; e.g. (E,E)-2,4-hexadiene affords stereospecifically the cis Diels-Alder adduct following the Woodward-Hoffmann rules. However, $(Z, Z)-2,4$-hexadiene affords the adduct with the "wrong" trans stereochemistry as major product. Furthermore, when the reaction is carried out in methanol, solvent trapping adducts are formed in a non-stereospecific manner. ${ }^{2}$ DFT theoretical calculations reported by Houk and Foote ${ }^{4}$ on dienes that easily adopt the s-cis conformation reveal that the concerted pathway is favored over a non-symmetrical transition state. For dienes that cannot easily adopt the s-cis conformation, a stepwise pathway operating via formation of an aziridinium imide (AI) 
intermediate is most probable. The AI can either afford an ene adduct, or transform into an open zwitterion. In the light of this theoretical work, we present a study on the isotope effect in the reaction of MTAD with the bulky 2,5-dimethyl-2,4-hexadiene (DMHD). The present results corroborate the calculations, and reveal new mechanistic details of this interesting reaction.

The reaction of DMHD 1 with PTAD 2a was originally reported by Gillis and Hagarty ${ }^{5}$ and was found to afford an acyclic addition product containing an acetoxy group. The authors suggest that the adduct is formed by trapping the possible dipolar intermediate with $\mathrm{Pb}(\mathrm{OAc})_{4}$ used to oxidize 4-phenylurazole to PTAD 2a. Later, Foote and Jensen ${ }^{2}$ have found when this reaction was carried out at low temperature $\left(-40{ }^{\circ} \mathrm{C}\right)$ in chloroform, a labile adduct with the possible structure of 1,2-diazetidine 3 was formed, which at higher temperature $\left(-10{ }^{\circ} \mathrm{C}\right)$ rearranged to the ene adduct 4 (Scheme 1). In addition, variable amounts of unidentified polymeric material were formed. In methanol this reaction was performed furnished a mixture of 1,4- and 1,2-methoxy adducts 5 and 6, respectively (ratio 80:20).

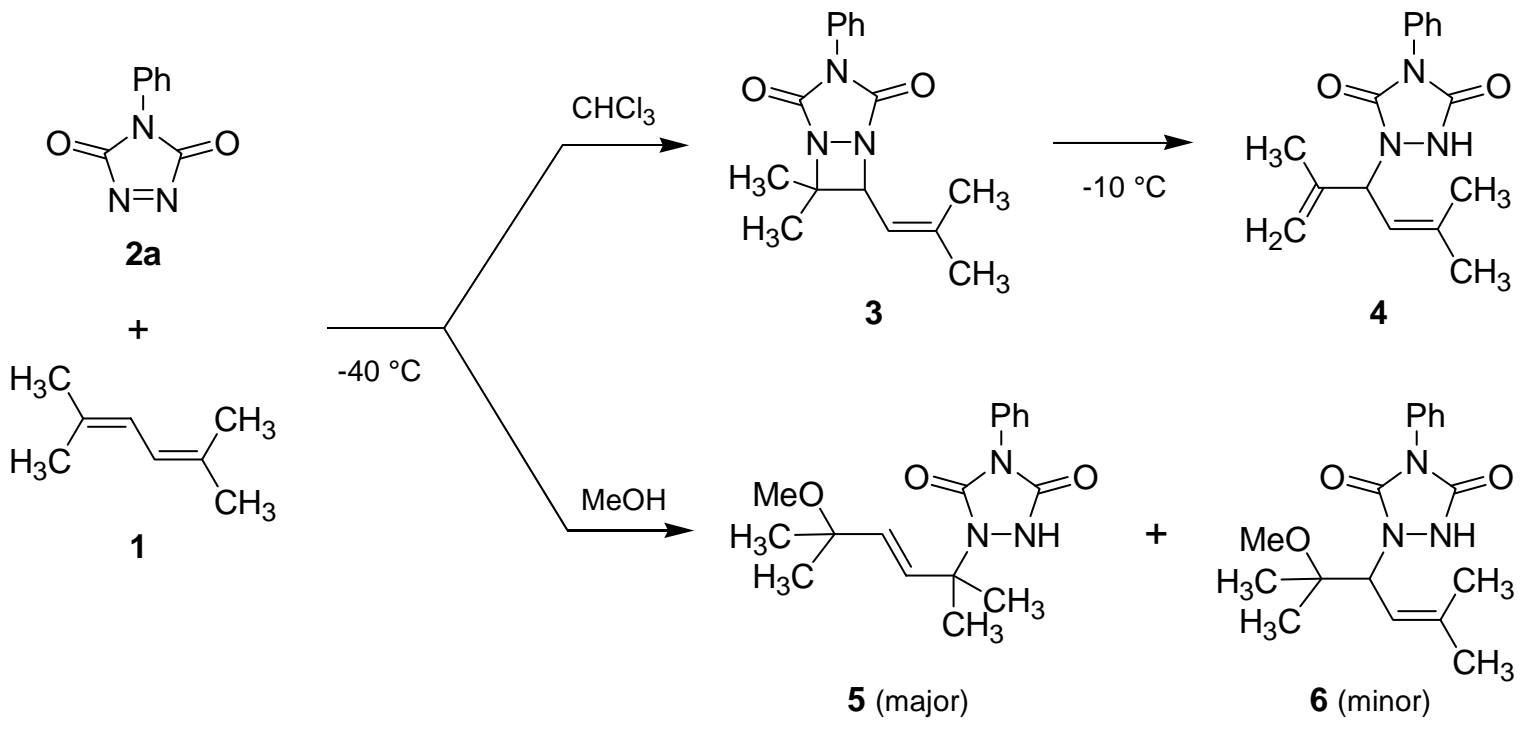

Scheme 1. Reaction of 2,5-dimethyl-2,4-hexadiene (1) with PTAD 2a in $\mathrm{CHCl}_{3}$ and $\mathrm{MeOH}$.

\section{Results}

To elucidate the energy profile, and to shed light on mechanistic details of this intriguing reaction, we determined the primary and secondary isotope effects for the two possible pathways (ene in $\mathrm{CHCl}_{3}$ and solvent trapping in methanol). For this purpose, 2,5-dimethyl-2,4-hexadiene$1,1,1,2^{\prime}, 2^{\prime}, 2^{\prime}-d_{6}\left(\mathbf{1}-d_{6}\right)$ with $g e m \mathrm{CD}_{3}$ groups was prepared according to a published procedure. ${ }^{6}$ 


\section{Reaction in chloroform}

For the addition of MTAD $\mathbf{2 b}$ to $\mathbf{1}$ in $\mathrm{CHCl}_{3}$, the main product was the ene adduct $\mathbf{4}(\mathrm{R}=\mathrm{Me})$, while significant amounts of unidentified by-products (polymeric material) were formed depending on the reaction temperature. When the reaction was carried out at low temperature (below $-30{ }^{\circ} \mathrm{C}$ ), the crude reaction mixture contained a substantial amount (major component) of unidentified by-products. However, when the reaction was carried out at higher temperature $\left(20^{\circ} \mathrm{C}\right)$ the amount of by-products was surprisingly minimized. Moreover, in boiling chloroform, the ene adduct is the only reaction product.

The reaction of $\mathbf{1}-d_{6}$ with MTAD $\mathbf{2} \mathbf{b}$ in $\mathrm{CDCl}_{3}$ reveals a temperature dependence of the primary isotope effect for the ene pathway (Scheme 2). At $-10{ }^{\circ} \mathrm{C}$ an intramolecular isotope effect of $\mathrm{k}_{\mathrm{H}} / \mathrm{k}_{\mathrm{D}}=3.12 \pm 0.10$ was determined, whereas at $63{ }^{\circ} \mathrm{C} \mathrm{k}_{\mathrm{H}} / \mathrm{k}_{\mathrm{D}}=1.85 \pm 0.05$. The isotope effect was obtained from signal integration of the terminal olefinic $\mathrm{H}^{1}$ at $\delta 5.04$ and $\mathrm{H}^{2}$ at $\delta 5.00$, corresponding to $2 \mathrm{k}_{\mathrm{H}}$, and that of the allylic proton signal $\mathrm{H}^{4}$ at the carbon attached to the urazol ring at $\delta 5.31$ or the olefinic hydrogen $\mathrm{H}^{3}$ at $\delta 5.22$, both corresponding to $\mathrm{k}_{\mathrm{H}}+\mathrm{k}_{\mathrm{D}}$.

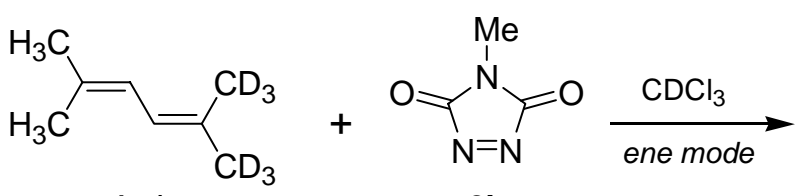

$1-d_{6}$ 2b

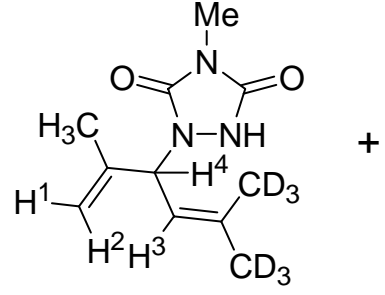

$7\left(\mathrm{k}_{\mathrm{H}}\right)$

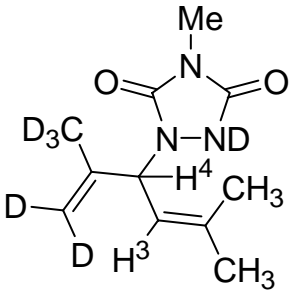

$8\left(k_{D}\right)$

\begin{tabular}{cc}
\hline${ }^{\circ} \mathrm{C}$ & $\mathrm{k}_{\mathrm{H}} / \mathrm{k}_{\mathrm{D}}$ \\
\hline-10 & $3.12 \pm 0.10$ \\
+25 & $2.10 \pm 0.07$ \\
+63 & $1.85 \pm 0.05$ \\
\hline
\end{tabular}

Scheme 2. Ene reaction of 1- $d_{6}$ with MTAD $\mathbf{2 b}$; temperature dependent primary isotope effect.

\section{Reaction in methanol}

The addition of MTAD $\mathbf{2 b}$ to $\mathbf{1}$ in methanol or in chloroform containing 10\% methanol afforded a mixture of 1,4- and 1,2-methoxy addition products $\mathbf{5 b}$ and $\mathbf{6 b}$, respectively (Scheme 3 ). These adducts arise from methanol intercepting the presumed intermediate(s). The trapping reaction is highly favored, even trace amounts of ethanol admixed to chloroform (in commercial solvent) intercept the intermediate(s) forming mainly ethoxy adducts, while the ene product is the minor reaction product. The ratio of adducts $\mathbf{5 b} / \mathbf{6 b}$ in methanol as determined by integration of significant ${ }^{1} \mathrm{H}$ NMR signals and by gas chromatography (GC) is temperature dependent. At higher temperatures the amount of the 1,2-adduct $\mathbf{6 b}$ formed is very small, but lowering the reaction temperature increases the relative yield of $\mathbf{6 b}$ substantially (Scheme 3). 
The reaction of $\mathbf{1}-d_{6}$ with MTAD $\mathbf{2 b}$ in methanol furnished mainly the 1,4-methanol addition products, and the $\beta$-secondary isotope effects were determined (Scheme 4). The 1,4-adduct 9 (with the new $\mathrm{C}-\mathrm{N}$ bond extended from the carbon atom bearing the geminal $\mathrm{CH}_{3}$ groups) is defined as $\mathrm{k}_{\mathrm{H}}$, and adduct 12 as $\mathrm{k}_{\mathrm{D}}\left(\mathrm{C}-\mathrm{N}\right.$ bond on the carbon atom bearing the geminal $\mathrm{CD}_{3}$ groups).

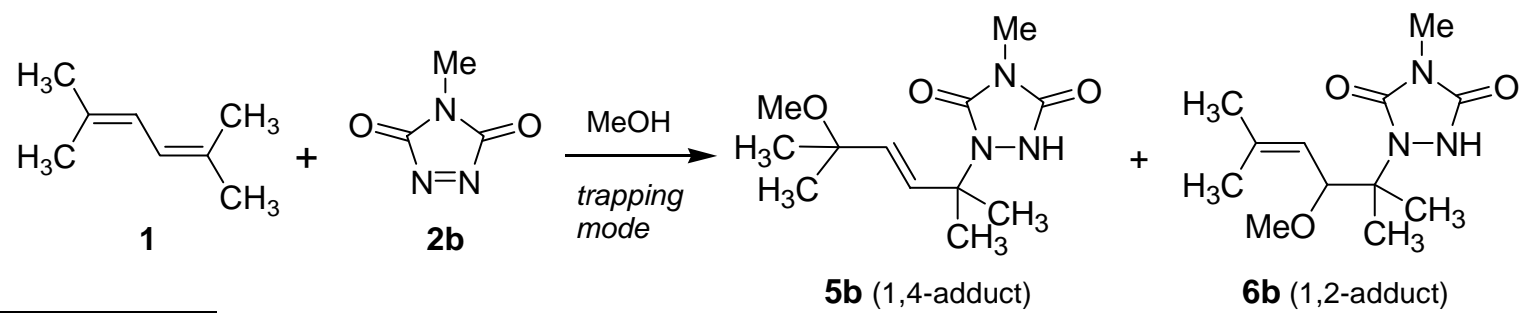

\begin{tabular}{cc}
\hline${ }^{\circ} \mathrm{C}$ & $5 \mathrm{~b} / 6 \mathrm{~b}$ \\
\hline-65 & $67 / 33$ \\
-40 & $74 / 26$ \\
-20 & $83 / 17$ \\
+20 & $87 / 13$ \\
\hline
\end{tabular}

Scheme 3. Temperature dependent formation of 1,4- and 1,2-methoxy trapping adducts $5 \mathbf{b}$ and $\mathbf{6 b}$.

At ambient temperature, the 1,4-adducts $\mathbf{9}$ and $\mathbf{1 0}$ were formed with a slightly inverse $\beta$ secondary isotope effect of $\mathrm{k}_{\mathrm{H}} / \mathrm{k}_{\mathrm{D}}=0.93 \pm 0.03$. The isotope effect was determined by measuring the integration of singlet signals at $\delta 1.29$ corresponding to $\mathrm{k}_{\mathrm{D}}$, and at $\delta 1.57$ corresponding to $\mathrm{k}_{\mathrm{H}}$. By lowering the temperature increases the isotope effect in favor of $\mathrm{k}_{\mathrm{D}}$, and at $-65^{\circ} \mathrm{C}$ it becomes $\mathrm{k}_{\mathrm{H}} / \mathrm{k}_{\mathrm{D}}=0.73 \pm 0.03$, or $\mathrm{k}_{\mathrm{D}} / \mathrm{k}_{\mathrm{H}}=1.37$. This value corresponds to $\mathrm{k}_{\mathrm{D}} / \mathrm{k}_{\mathrm{H}}=1.06 \pm 0.01$ per $\mathrm{D}$ atom.

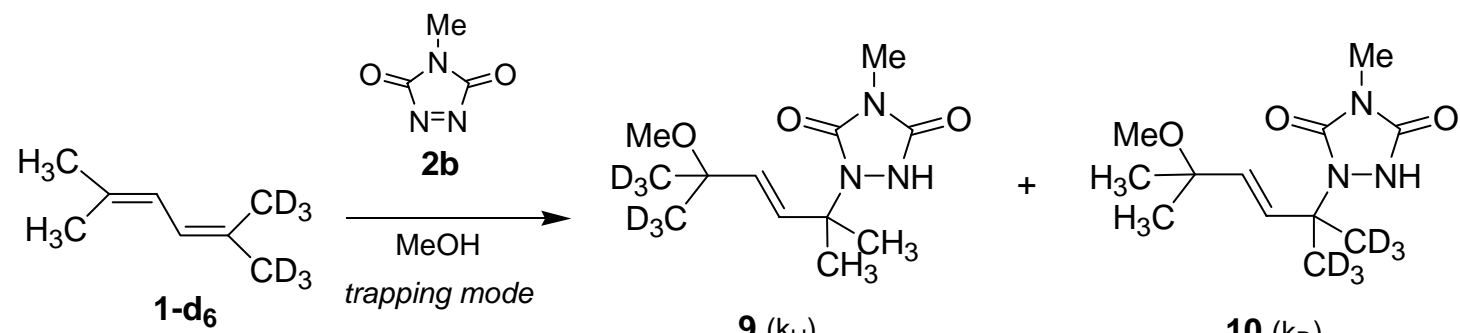

\begin{tabular}{cc}
\hline${ }^{\circ} \mathrm{C}$ & $\mathrm{k}_{\mathrm{H}} / \mathrm{k}_{\mathrm{D}}$ \\
\hline-65 & $0.73 \pm 0.03$ \\
-40 & $0.78 \pm 0.03$ \\
-20 & $0.85 \pm 0.03$ \\
+20 & $0.93 \pm 0.03$ \\
\hline
\end{tabular}

Scheme 4. $\beta$-Secondary isotope effect for the 1,4-trapping mode in the reaction of 1- $d_{6}$ with MTAD $\mathbf{2 b}$ in methanol. 


\section{Discussion}

The significant feature of this reaction ${ }^{7}$ are the temperature dependent changes according to the following observations: (i) the ratio of the ene versus the polymeric byproduct in chloroform; (ii) the primary isotope effect for the ene pathway in chloroform; (iii) the ratio of the 1,2-/1,4methoxy trapping adducts $\mathbf{5 b} / \mathbf{6 b}$ in methanol; and (iv) the $\beta$-secondary isotope effect for the 1,4trapping mode in methanol.

In order to explain these changes, we consider the formation of two intermediates, bicyclic aziridinium imides AI and open zwitterions ZI. The nature of these intermediates affects significantly the outcome of the reaction. The open zwitterion $\mathbf{Z I}$ is entropically more favorable compared to AI. At low temperatures, formation of the entropy-favored zwitterion ZI occurs preferentially. For steric reason, the zwitterionic intermediate ZI cannot lead to a [4+2] cycloadduct; instead, it polymerizes. At higher temperatures, formation of the aziridinium imide AI prevails giving rise to a very clean reaction (only the ene product is formed).

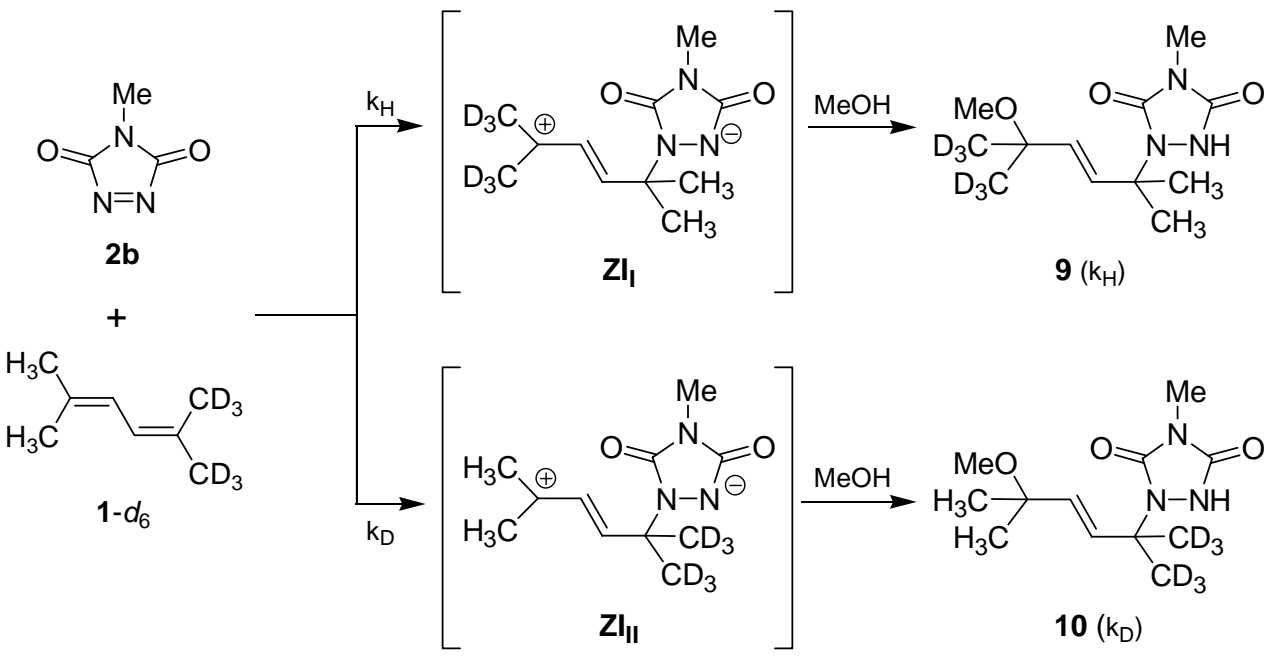

Scheme 5. Zwitterionic intermediates ZI in the reaction of 1- $d_{6}$ with MTAD 2b in methanol.

The significant primary isotope effect of the ene reaction of 1- $d_{6}$ with MTAD $2 \mathbf{b}$ indicates that hydrogen atom abstraction occurs in the rate-determining step. The temperature dependence of the isotope effect indicates the existence of a tunneling effect. Probably, this effect results from the severe steric hindrance in the transition state of the second rate-determining step (intramolecular hydrogen transfer) of the ene reaction. A similar tunneling effect has been already recognized in the ene reaction of PTAD 2a with gem tetramethylethylene- $d_{6}{ }^{8}$

The temperature dependence of the $\beta$-secondary isotope effect for the 1,4-trapping mode of the reaction in methanol (Scheme 4) can be explained as follows. At low temperature $\left(-65^{\circ} \mathrm{C}\right)$, the entropically favored open zwitterion ZI is formed preferentially relative to AI. Among the two possible zwitterionic intermediates $\mathbf{Z} \mathbf{I}_{\mathbf{I}}$ and $\mathbf{Z I}_{\mathbf{I I}}$ (Scheme 5), the latter prevails due the better 
hyperconjugative stabilization of the carbocation by the $\mathrm{CH}_{3}$ groups relative to the $\mathrm{CD}_{3}$ groups. Reaction of methanol with $\mathbf{Z I}_{\mathbf{I}}$ and $\mathbf{Z I}_{\text {II }}$ forms a mixture of adducts $\mathbf{9}$ and $\mathbf{1 0}$ (ratio 1.37:1). Similar values of an inverse isotope effect were measured for the [2+2] cycloaddition reaction of TCNE with 1-d ${ }^{9}{ }^{9}$ At higher temperatures, formation of the aziridinium imide intermediate AI predominates. The two possible intermediates $\mathbf{A I}_{\mathbf{I}}$ and $\mathbf{A I}_{\mathbf{I I}}$, shown below, are expected to be formed in almost equal amounts. Reaction of methanol with $\mathbf{A I}_{\mathbf{I}}$ and $\mathbf{A} \mathbf{I}_{\mathbf{I I}}$, in a Michael type addition, will eventually form the 1,4-adducts $\mathbf{9}$ and $\mathbf{1 0}$ with a negligible isotope effect. We assume that the slightly inverse $\mathrm{k}_{\mathrm{H}} / \mathrm{k}_{\mathrm{D}}$ values found if the methoxy-trapping reaction occurs at ambient temperature may be mostly due to steric reasons (the approach of MTAD to form $\mathbf{A I}_{\mathbf{I I}}$ is expected to be slightly more favorable from the steric point of view, since the $\mathrm{CH}_{3}$ is slightly more bulkier than the $\mathrm{CD}_{3}$ group).

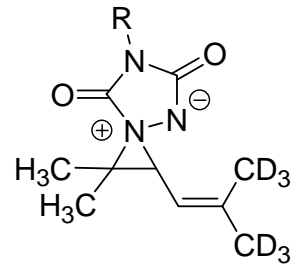

$\mathrm{Al}_{\mathbf{I}}$

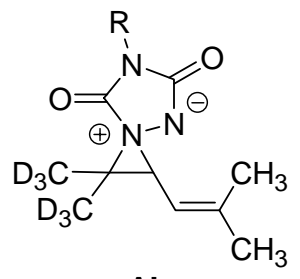

$\mathrm{Al}_{\mathbf{I I}}$

A general mechanistic overview, as described in the discussion above, is presented in Scheme 6.

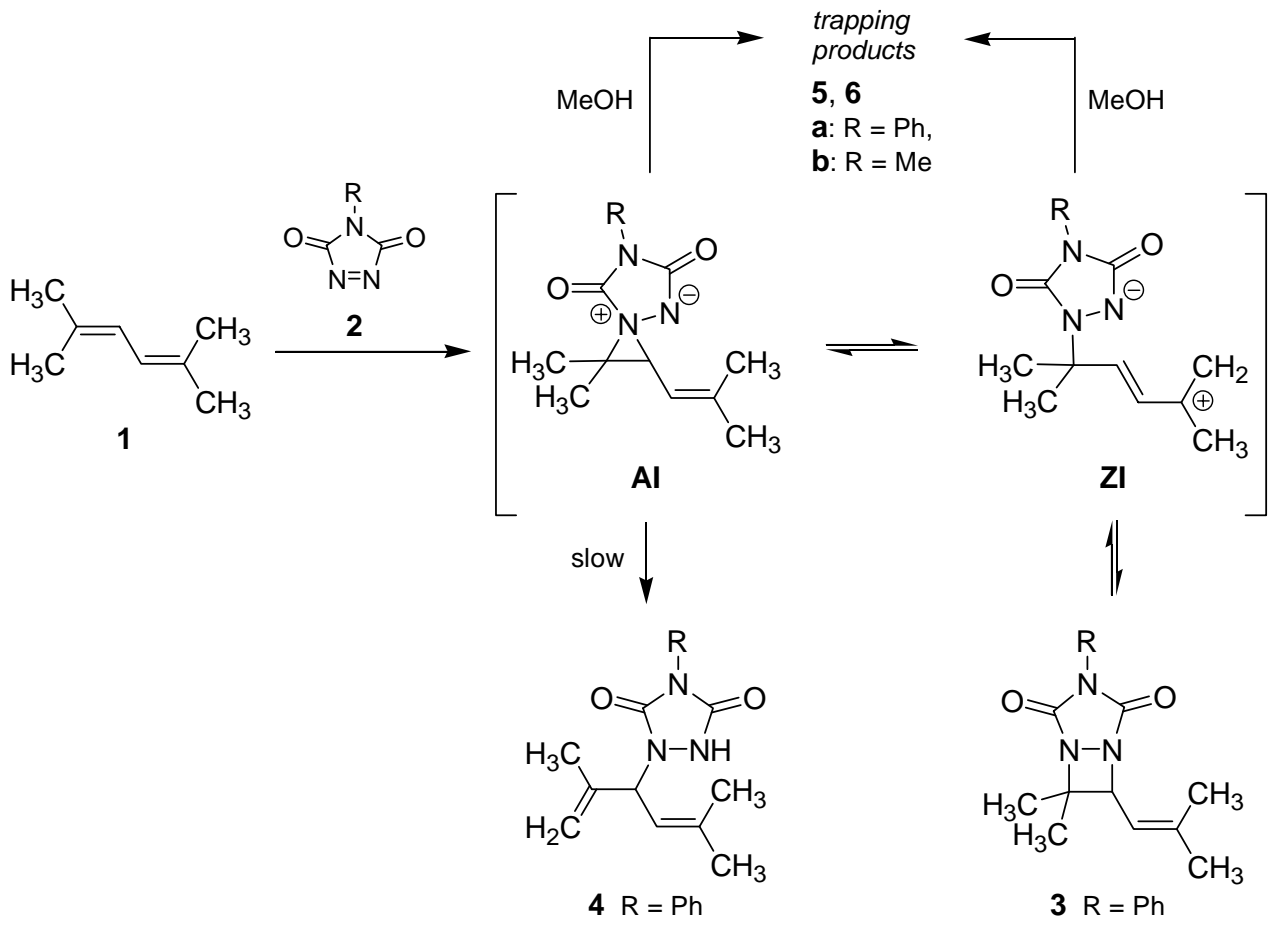

Scheme 6. Proposed mechanism for the reaction of 2,5-dimethyl-2,4-hexadiene 1 with triazolinediones 2. 
In conclusion, based on primary and secondary isotope effects, we elucidated the energy profile for the reaction of triazolinediones 2 with 2,5-dimethyl-2,4-hexadiene $\mathbf{1}$. In addition, the present results corroborate the previous assumption for the intermediacy of an aziridinium imide AI and an open zwitterionic intermediate $\mathbf{Z I}$.

\section{Acknowledgements}

This work was supported in part by the Greek Secretariat of Research and Technology.

\section{Experimental Section}

General Procedures. Nuclear magnetic resonance spectra were recorded on a $500 \mathrm{MHz}$ spectrometer, in $\mathrm{CDCl}_{3}$. Isomeric purities were determined by ${ }^{1} \mathrm{H}$ NMR spectroscopy and by analytical gas chromatography on an SP-5 capillary column. 4-Methyl[1,2,4]triazoline-3,5-dione (MTAD, 2b) is commercially available, 2,5-dimethyl-2,4-hexadiene-1,1,1,2',2',2'- $d_{6}\left(\mathbf{1}-d_{6}\right)$ was prepared as described earlier. ${ }^{6}$

The reaction of $\mathbf{1}-d_{6}$ with MTAD $2 \mathbf{b}$ using equimolar amounts of the starting materials in $\mathrm{CDCl}_{3}$ and in $\mathrm{MeOH}$ were performed at different temperatures. The reaction products were purified by flash column chromatography using a mixture of hexane/EtOAc $=1: 1$ as eluent. The spectral data of the MTAD addition products are similar to the PTAD analogues. ${ }^{2}$

Mixture of 1-(1-isopropenyl-3-methylbut-2-enyl)-4-methyl[1,2,4]triazolidine-3,5-diones $\boldsymbol{d}_{6}$ (7) and (8). ${ }^{1} \mathrm{H} \mathrm{NMR}\left(500 \mathrm{MHz}, \mathrm{CDCl}_{3}\right): \delta 1.71(\mathrm{~d}, J=1.0 \mathrm{~Hz}, 3 \mathrm{H}, 8), 1.78(\mathrm{~d}, J=0.9 \mathrm{~Hz}, 3 \mathrm{H}$, 8), $1.79(\mathrm{~s}, 3 \mathrm{H}, 7), 3.03(\mathrm{~s}, 3 \mathrm{H}, 7$, and $3 \mathrm{H}, 8), 5.00(\mathrm{~s}, 1 \mathrm{H}, 7), 5.04(\mathrm{br} \mathrm{s}, 1 \mathrm{H}, 7), 5.22(\mathrm{~d}, J=8.9$ $\mathrm{Hz}, 1 \mathrm{H}, 7$, and $1 \mathrm{H}, 8), 5.31(\mathrm{~d}, J=8.9 \mathrm{~Hz}, 1 \mathrm{H}, 7$, and $1 \mathrm{H}, 8)$.

1-[(2E)-4-Methoxy-1,1,4-trimethylpent-2-enyl]-4-methyl[1,2,4]triazolidine-3,5-dione (5b). ${ }^{1} \mathrm{H}$ NMR (500 MHz, $\left.\mathrm{CDCl}_{3}\right): \delta 1.29(\mathrm{~s}, 6 \mathrm{H}), 1.57$ (s, 6H), 3.02 (s, 3H), 3.15 (s, 3H), 5.70 (AB, $\Delta \delta=0.17$ ppm, $J=16.2 \mathrm{~Hz}, 2 \mathrm{H}), 8.90$ (br s, NH).

1-(2-Methoxy-1,1,4-trimethylpent-3-enyl)-4-methyl[1,2,4]triazolidine-3,5-dione $\quad(6 \mathbf{b}) . \quad{ }^{1} \mathrm{H}$ NMR (500 MHz, $\left.\mathrm{CDCl}_{3}\right): \delta 1.42(\mathrm{~s}, 3 \mathrm{H}), 1.51(\mathrm{~s}, 3 \mathrm{H}), 1.73(\mathrm{~d}, J=1.2 \mathrm{~Hz}, 3 \mathrm{H}), 1.82(\mathrm{~d}, J=1.1$ $\mathrm{Hz}, 3 \mathrm{H}), 3.03$ (s, 3H), 3.22 (s, 3H), 4.10 (d, $J=9.8 \mathrm{~Hz}, 1 \mathrm{H}), 5.04$ (br d, $J=9.8 \mathrm{~Hz}, 1 \mathrm{H}), 8.65$ (br $\mathrm{s}, \mathrm{NH})$.

Mixture of 1-[(2E)-4-methoxy-1,1,4-trimethylpent-2-enyl]-4-methyl[1,2,4]triazolidine-3,5diones $\boldsymbol{d}_{\mathbf{6}}(\mathbf{9})$ and (10). ${ }^{1} \mathrm{H} \mathrm{NMR}\left(500 \mathrm{MHz}, \mathrm{CDCl}_{3}\right): \delta 1.29(\mathrm{~s}, 6 \mathrm{H}, \mathbf{1 0}), 1.57(\mathrm{~s}, 6 \mathrm{H}, 9), 3.02(\mathrm{~s}$, $3 \mathrm{H} \mathrm{9}$, and $3 \mathrm{H}, \mathbf{1 0}), 3.15(\mathrm{~s}, 3 \mathrm{H}, \mathbf{9}$, and $3 \mathrm{H}, \mathbf{1 0}), 5.70(\mathrm{AB}, \Delta \delta=0.17 \mathrm{ppm}, J=16.2 \mathrm{~Hz}, 2 \mathrm{H}, 9$ and $2 \mathrm{H}, \mathbf{1 0}), 8.90$ (br s, NH). 


\section{References}

1. Radl, S. Adv. Heterocycl. Chem. 1997, 67, 119.

2. Jensen, F.; Foote, C. S. J. Am. Chem. Soc. 1987, 109, 6376.

3. Clennan, E. L.; Earlywine, A. D. J. Am. Chem. Soc. 1987, 109, 7104.

4. Chen, J. S.; Houk, K. N.; Foote, C. S. J. Am. Chem. Soc. 1998, 120, 12303.

5. Gillis, B. T.; Hagarty, J. D. J. Org. Chem. 1967, 32, 330.

6. Vassilikogiannakis, G.; Stratakis, M.; Orfanopoulos, M. J. Org. Chem. 1998, 63, 6390.

7. For a preliminary acount of the 1,4-methoxy trapping reaction, see: Vassilikogiannakis, G.; Stratakis, M.; Karabatsos, G. J.; Orfanopoulos, M. J. Heterocycl. Chem. 1996, 33, 993.

8. Elemes, Y.; Orfanopoulos, M. J. Am. Chem. Soc. 1992, 111, 11007.

9. Vassilikogiannakis, G.; Orfanopoulos, M. Tetrahedron Lett. 1996, 37, 3075. 